\title{
Electrical Discharge Machining of SiC Reinforced 6061-T6 Aluminum Alloy Surface Composite Fabricated by Friction Stir Processing
}

\author{
Murahari Kolli' ${ }^{1}$, Devaraju Aruri,,*, Saikumar Gadakary², and Satyanarayana Kosaraju ${ }^{3}$ \\ ${ }^{1}$ Department of Mechanical Engineering, Lakireddy Bali Reddy College of Engineering, Kakinada, India \\ ${ }^{2}$ Department of Mechanical Engineering, Kakatiya Institute of Technology and Science, Warangal, India \\ ${ }^{3}$ Department of Mechanical Engineering, Gokarajau Rangaraju Institute of Engineering and Technology, Hyderabad, India
}

\begin{abstract}
Engineered materials with high hardness, great wear tolerance, high high-temperature power, and a low thermal expansion coefficient are aluminum-based composites. These materials are widely used in the automotive and aerospace industries. Friction stir processing (FSP) method used to prepare $\mathrm{SiC}$ reinforced aluminium alloy surface composite. Material removal rate (MRR) and surface roughness (SR) are measured with the impact of pulse on time, discharge current, and pulse off time (add one or two outcomes remark at SR and MRR optimal condition) is examined. For each of the three machining parameters, L9 orthogonal arrays (OA) of three levels were used in conducting the experiments. The validity of the Aluminum Surface Composite experiment programme is determined using MINITAB.
\end{abstract}

Keywords: EDM, Current, Surface roughness, Metal removal rate, Pulse on time and Pulse off time

\section{Introduction}

Metal matrix composites (MMCs) are distinct type of composite material that is increasingly being utilised in architecture and manufacturing. MMCs are utilised in many industries, including aircraft, cars, construction, electronics, defense, sports goods, and technical components. In order to meet the specific demands of MMC products, composite materials have been developed that are made up of two or more distinct physical and chemical substances. The reinforcement refers to the discontinuous phase, while the matrix refers to the continuous-time. The advanced materials are light, have high specific power, are resistant to wear, and have a low coefficient of thermal expansion. Aluminium metal matrix composites (MMCs) are extensively utilised in the automotive (brake drum, cylinder liners, cylinder base, and driveshaft) and aerospace sectors because of their high strength, shatter resistance, wear tolerance, and endurance (helicopter components of the chassis, rotor vane, and aero-engines). Furthermore, AlMMCs reinforced by ceramics such as $\mathrm{SiC}$ and $\mathrm{Al} 2 \mathrm{O} 3$ demonstrated better long-term strength [2-3]. These ceramic particles reinforced Aluminum alloy composites are utilised in applications that need both wear resistance and weight reduction. Aluminum alloy 6061-T6 composites are often used in aviation, safety, cars, and boats because to their improved corrosion and lightweight.
EDM's objectives include producing different physical and mechanical phases from a composite material. When examining these reinforcements, you will see they have different characteristics in their melting points and thermal conductivity. In EDM operations, Comosits'

high thermal conductivity allows for good resistance and efficiency. M.Selvakumar et al. [4] (2012) studied EDM of sand cast $6061 \mathrm{Al} / \mathrm{SiC}$ composites. The models were developed to demonstrate the effect of machining variables such as pulse off time, pulse on time, peak current, wear intensity, and dielectric fluid on MRR and SR. The surface polish and metal removal rate (MRR) improve with increasing current, while the MRR decreases with increasing silicon content in hardened particles. M. In experimental research, Rozenek et al [5] looked at the effects of machining factors on aluminium alloy $\mathrm{SiC}$ and $\mathrm{Al}_{2} \mathrm{O}_{3}$-related composite materials. As the discharge current and pulse on-time rose, the surface roughness increased as well. TWR and MRR drop when electrical conductivity and thermal conductivity decreases. In aluminium composite content EDM, R. Karthikeyan et al. [6] established a statistical model to optimise process variables. The TWR and SR both decreased as the $\mathrm{SiC}$ particle concentration increased. As the volume $\%$ of $\mathrm{SiC}$ particles rose, the TWR and SR were observed to decrease. According to the results, MRR increases as current increases and reduces as $\mathrm{SiC}$ particle reinforcement increases.

However, no EDM findings for FSP-fabricated $\mathrm{Al} / \mathrm{SiC}$ 6061-T6 surface composite have been found. Optimizing

\footnotetext{
* Corresponding author: aruri_devaraj@yahoo.com
} 
process parameters to enhance $\mathrm{MMR}$ and $\mathrm{SR}$ of a $\mathrm{Al} / \mathrm{SiC}$ 6061-T6 surface composite was not mentioned. The Taguchi is a method to plan and evaluate studies with the goal of increasing efficiency [7-9]. It is already a commonly used realistic technique for improving performance efficiency and decreasing the number of experiments, thereby cutting the cost of testing. A Devaraju et al. [10] optimised the mechanical and wear characteristics of $\mathrm{Al}-\mathrm{SiC} / \mathrm{Gr}$ surface hybrid composites using the Taguchi method.

The FSP technique is used in this work to reinforce aluminium 6061-T6 alloy metal matrix composite of $12 \% \mathrm{SiC}$ volume particles using the FSP method. EDM on an surface composite Al6061-SiC is carried out using dielectric solvent with EDM oil and electrolyte copper with a $10 \mathrm{~mm}$ diameter. The main aim of the present study is, to investigate how EDM parameters like pulse on time, discharge current and pulse off time influence SR and MRR, using the method Taguchi to identify the optimum combinations.

\section{Experiment Details}

\subsection{FSP of Al-SiC surface composite}

Aluminium alloy 6061-T6, which is $4 \mathrm{~mm}$ thick, was utilised as the foundation material in this study. Table-1 shows chemical structure of the basic material. On average, the $\mathrm{SiC}$ reinforcements are 20 metres long. A 3 $\mathrm{mm}$ width and $3 \mathrm{~mm}$ depth square groove was in tangent to the pin in the state of advancing hand with $1 \mathrm{~mm}$ distant from the tool rotation's centre line over the Aluminum alloy of 6061-T6 shield. Screwed taper pin profile on the aluminium alloy plate to perform FSP was manufactured from tool steel $\mathrm{H} 13$ and had $24 \mathrm{~mm}$ shoulder diameter, $8 \mathrm{~mm}$ pin diameter, and $3.5 \mathrm{~mm}$ height. At a volume percentage of $12 \%$, the groove was filled with $\mathrm{SiC}$ particles. The groove hole was initially closed using a tool with a shoulder without a lock to prevent reinforcing particles from escaping during production. FSP utilised a tool with a $40 \mathrm{~mm} / \mathrm{min}$ movement speed, a $5 \mathrm{KN}$ axial force, and a 2.50 forward tilt angle around the centre line. The experiments are performed using vertical milling system (HMT FM-2, 10 HP, 3000 RPM) [10].

Table 1: Chemical composition of Aluminum 6061-T6 alloy (Wt. \%)

\begin{tabular}{|l|l|l|l|l|l|l|l|l|}
\hline Element & $\mathrm{Mg}$ & $\mathrm{Si}$ & $\mathrm{Cu}$ & $\mathrm{Zn}$ & $\mathrm{Ti}$ & $\mathrm{Mn}$ & $\mathrm{Cr}$ & $\mathrm{Al}$ \\
\hline $\begin{array}{l}\text { Amount } \\
\text { (W\%) }\end{array}$ & .85 & .68 & .022 & 07 & 05 & .032 & .0 & Balance \\
\hline
\end{tabular}

Experiments were conducted using a PSR-20 power supply and die-sinking EDM type 50. The DC servo control is used to fed electrode downwards into the workpiece. In the tests, positive polarity electrodes were utilised. The electrode is made of copper with a $10 \mathrm{~mm}$ diameter and $70 \mathrm{~mm}$ length. A workpiece of $100 \mathrm{~mm}$ long, $20 \mathrm{~mm}$ wide, and $4 \mathrm{~mm}$ thick is utilised. It takes 4 minutes to complete the machining operation. Before and after the commencement of machining, the workpiece weight is determined using a digital balance (manufactured by Citizen). Surface roughness is calculated with the help of the Handysurf tool. Tables-2 and Table- 3 shows the usual working conditions of EDM and material characteristics of surface composites 6061T6 Al/ SiCp.

Table 2: EDM working conditions

\begin{tabular}{|c|c|}
\hline Working conditions & Description \\
\hline Work piece & 12Vol\%SiC T6-6061 \\
\hline Electrode material & Electrolyte copper \\
\hline Electrode polarity & Reverse \\
\hline Working time & 4 min \\
\hline Discharge Gap & 70 Microns \\
\hline Discharge current & $0-8 \mathrm{~A}$ \\
\hline Discharge open voltage & $110+[5 \mathrm{~V}$ \\
Discharge gap current & $40 \mathrm{~V}$ \\
Pulse on time & $0-90 \mu \mathrm{s}$ \\
Pulse off time & $0-60 \mu \mathrm{s}$ \\
Dielectric oil & EDM Oil \\
Dielectric pressure & $0.5 \mathrm{Mpa}$ \\
\hline
\end{tabular}

Table 3: 6061-T6 Al/ $\mathrm{SiC}_{\mathrm{p}}$ surface composite properties

\begin{tabular}{|l|l|l|l|l|l|}
\hline $\begin{array}{l}\text { Materi } \\
\text { al }\end{array}$ & $\begin{array}{l}\text { Micro } \\
\text { Hardnes } \\
\mathrm{s}\end{array}$ & $\begin{array}{l}\text { UT } \\
\text { Strength }\end{array}$ & $\begin{array}{l}\text { Yield } \\
\text { Strength }\end{array}$ & $\begin{array}{l}\text { \%Elon } \\
\text { gation }\end{array}$ & $\begin{array}{l}\text { Den } \\
\text { sity } \\
(\mathrm{g} / \mathrm{c} \\
\left.\mathrm{m}^{3}\right)\end{array}$ \\
\hline $\begin{array}{l}\text { 6061- } \\
\mathrm{T} 6 \mathrm{Al} / \mathrm{S} \\
\mathrm{iC}_{\mathrm{p}}\end{array}$ & $125(\mathrm{HV})$ & $157(\mathrm{Mpa}$ & $115(\mathrm{Mpa}$ & 7.2 & 2.76 \\
\hline
\end{tabular}

\subsection{Evaluation of MRR and SR}

The following parameters are typically used to evaluate EDM efficiency, regardless of the electrode material and dielectric fluid used:

- Metal removal rate (MRR) in millimeters per minute $(\mathrm{mm} 3 / \mathrm{min})$

- Roughness of the Surface $(\mathrm{Ra})(\mu)$

The equation below is used to calculate the MRR: 
The maximum MRR is a valuable measure of the EDM process's performance and cost-effectiveness; nevertheless, in all the applications rising MRR may not be always optimal since it may compromise the integrity of workpiece's surface. Quick removal rates result in a rough surface finish. The equation below is often used to calculate the MRR value.

$\left.\operatorname{MRR}=\operatorname{MRR}\left(\mathrm{mm}^{3} / \mathrm{min}\right)=\left(\mathrm{W}_{\mathrm{b}}-\mathrm{W}_{\mathrm{a}}\right) \times 1000\right) /\left(\rho \times \mathrm{T}_{\mathrm{m}}\right)$

Where,

$\mathrm{W}_{\mathrm{b}}=$ workpiece material weight before machining $(\mathrm{g})$

$\mathrm{W}_{\mathrm{a}}=$ workpiece material weight after machining $(\mathrm{g})$

$\mathrm{T}_{\mathrm{m}}=$ time of machining $(\mathrm{min})$

$\rho_{\mathrm{w}}=$ workpiece material density $\left(\mathrm{g} / \mathrm{cm}^{3}\right)$

\subsection{Experimental Plan based on Taguchi's Method}

One of the most important parameters in EDM is current, over which MRR is highly affected on Al-SiC surface composites [4-6]. Sample experiments were carried out to establish the working range by changing the current, Ton, and Toff while keeping the other variables constant. The technique parameter values that were deemed viable were chosen to produce a defect-free Al-surface composite. The existing range, $\mathrm{T}_{\text {on }}, \mathrm{T}_{\text {off }}$, and constant process parameter ranges are tabulated in Tables 3 and 4 .

Table 4: Working range of the selected parameters

\begin{tabular}{|l|l|l|l|l|l|}
\hline Symbol & \multirow{2}{*}{ Parameters } & Units & & level & \\
\cline { 4 - 6 } & & & (1) & (2) & (3) \\
\hline $\mathrm{A}$ & Current & $\mathrm{A}$ & 4 & 6 & 8 \\
\hline $\mathrm{B}$ & $\mathrm{T}_{\text {on }}$ & $\mu \mathrm{s}$ & 25 & 55 & 80 \\
\hline $\mathrm{C}$ & $\mathrm{T}_{\text {off }}$ & $\mu \mathrm{s}$ & 16 & 38 & 56 \\
\hline
\end{tabular}

Taguchi's approach is particularly helpful when dealing with responses that are influenced by a number of variables. It's a simple, efficient, and thorough technique for finding the optimum process parameters. It reduces the number of trials required, which makes it a good design experiments technique for modelling and refining responses. Experiments are also saved lots of time and money. Taguchi technique [7-9] was designed for optimization of the process and the determination of optimum process parameters values. The Taguchi technique is used to transform the signal-to-noise $(\mathrm{S} / \mathrm{N})$ ratio from experimental values of various responses. Maximisation retort is referred to as "higher is better," while minimization response is referred to as "lower is better". Taguchi calculates the mean value to the divergence of the answer from using the $\mathrm{S} / \mathrm{N}$ ratio. $\mathrm{S} / \mathrm{N}$ ratios are calculated using Equation 2 for 'Higher the better' and Equation 3 for 'Lower the better' features. $\eta=-10 \log _{10}\left[\frac{1}{n} \sum_{i=1}^{n} \frac{1}{y_{i}^{2}}\right]-----$

Where,

$\eta-\mathrm{S} / \mathrm{N}$ ratio of experimental values,

$y_{i}$ - experimental value of the $i^{\text {th }}$ experiment and

$\mathrm{n}$ - total number of experiments.

$$
\eta=-10 \log _{10}\left[\frac{1}{n} \sum_{i=1}^{n} y_{i}^{2}\right]----
$$

The Taguchi technique is used for experimental data in this study with the help of MINITAB. This study takes into account three process parameters, each of which has three levels. For all three variables the degree of freedom is 6 . The orthogonal array $L_{9}\left(3^{3}\right)$ is selected. Every experiment state was repeated three times to decrease error/noise findings. Table 5 shows orthogonal sequence selected. Consistency features of $\mathrm{Al}-\mathrm{SiC}_{\mathrm{p}}$ surface composites as surface roughness (SR) and metal removal rate (MRR) were assessed in both experiments. The most effective element combinations have been predicted and confirmed.

Table 5: Experimental layout $\mathrm{L}_{9}\left(3^{3}\right)$ and Result with S/N Ratios

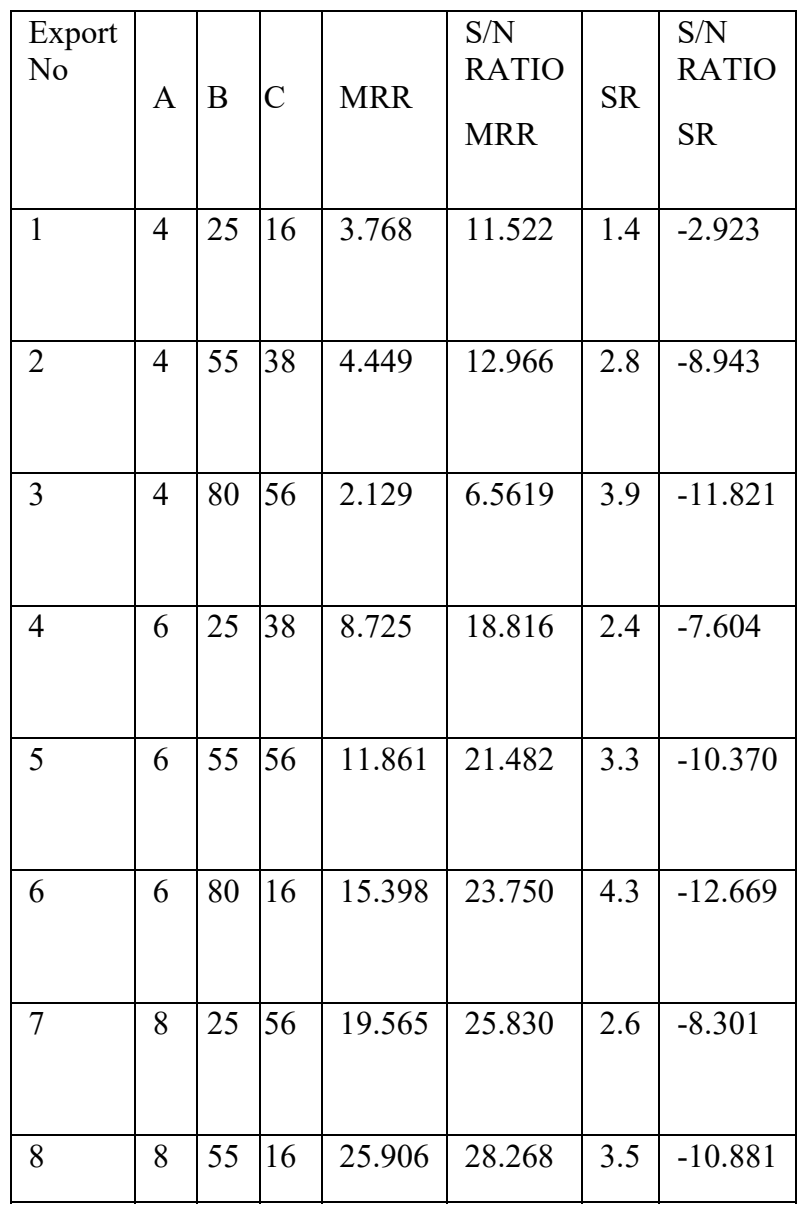




\begin{tabular}{|l|l|l|l|l|l|l|l|}
\hline & & & & & & & \\
\hline 9 & 8 & 80 & 38 & 14.968 & 23.503 & 4.3 & -12.670 \\
\hline
\end{tabular}

\section{Results Analysis and Discussion}

Investigational research was performed on 6061-T6 Al/ $\mathrm{SiCp}$ surface composite to examine the effect of machining parameters such as pulse off time, pulse on time and discharge current using electrical discharge machining.

Table 6: S/N Response table for MRR

\begin{tabular}{|l|l|l|l|}
\hline Levels & Current & $\begin{array}{l}\text { Pulse on } \\
\text { time }\end{array}$ & Pulse off time \\
\hline 1 & 10.35 & 18.72 & 21.18 \\
\hline 2 & 21.35 & 20.91 & 18.43 \\
\hline 3 & 25.87 & 17.94 & 17.96 \\
\hline Delta & 15.52 & 2.97 & 3.22 \\
\hline Rank & 3 & 2 & 1 \\
\hline
\end{tabular}

Table 7: S/N Response table for SR

\begin{tabular}{|l|l|l|l|}
\hline Levels & Current & $\begin{array}{l}\text { Pulse on } \\
\text { time }\end{array}$ & $\begin{array}{l}\text { Pulse off } \\
\text { time }\end{array}$ \\
\hline 1 & -7.896 & -6.275 & 19.106 \\
\hline 2 & -10.215 & -10.06 & -9.739 \\
\hline 3 & -10.617 & -12.387 & -10.164 \\
\hline Delta & 2.721 & 6.111 & 1.339 \\
\hline Rank & 1 & 1 & 1 \\
\hline
\end{tabular}

Table 8: Optimum values of the quality characteristics

\begin{tabular}{|l|l|l|l|l|}
\hline $\begin{array}{l}\text { Quality } \\
\text { characteristic } \\
\mathrm{s}\end{array}$ & $\begin{array}{l}\text { Signal } \\
\text { to } \\
\text { Noise } \\
\text { Ratio } \\
\text { values }\end{array}$ & $\begin{array}{l}\text { Predicte } \\
\mathrm{d} \text { values }\end{array}$ & $\begin{array}{l}\text { Optimu } \\
\mathrm{m} \\
\text { conditio } \\
\mathrm{n}\end{array}$ & $\begin{array}{l}\text { Optimu } \\
\mathrm{m} \text { value }\end{array}$ \\
\hline $\begin{array}{l}\text { Material } \\
\text { Removal } \\
\text { Rate }\end{array}$ & 28.26 & 29.575 & $\begin{array}{l}8-55- \\
16(3-2- \\
1)\end{array}$ & 25.906 \\
\hline $\begin{array}{l}\text { Surface } \\
\text { Roughness }\end{array}$ & -2.923 & -3.844 & $\begin{array}{l}4-25- \\
16(1-1-\end{array}$ & 1.4 \\
& & & $1)$ & \\
\hline
\end{tabular}

The forementioned equations may be used to calculate the values of machining performance for each experiment of the L9 orthogonal array to determine the $\mathrm{S} / \mathrm{N}$ ratio (Table 5). The major effect values obtained from the computation of the main impact for each level of the variables are shown in Tables 6 and 7. The primary effect graphic shows how each factor level influences machining efficiency. The optimum levels of a particular component are selected as person levels that contribute to the plot.

Table 5 shows how the average impact reaction valve and typical $\mathrm{S} / \mathrm{N}$ response ratios for $\mathrm{SR}$ and MRR were calculated using experimental data and $\mathrm{S} / \mathrm{N}$ ratio valves. Figures 1 and 2 shows the $\mathrm{S} / \mathrm{N}$ ratio response graphs for MRR and SR. The efficiency of valves with a increased $\mathrm{S} / \mathrm{N}$ ratio has increased. As a consequence, the parameter values with the high $\mathrm{S} / \mathrm{N}$ ratio valves are the best. Table 8 summarises the study's results.

\subsection{Effect of process parameters on MRR}

Fig 1 shows $\mathrm{S} / \mathrm{N}$ ratio of material removal rate (MRR) for the main effect plot with process parameters.

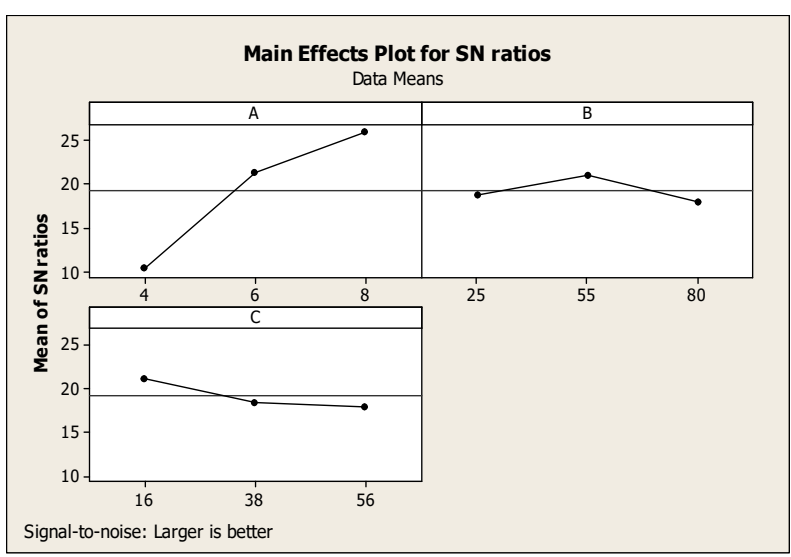

Fig 1: Main effect plot for $\mathrm{S} / \mathrm{N}$ ratios MRR

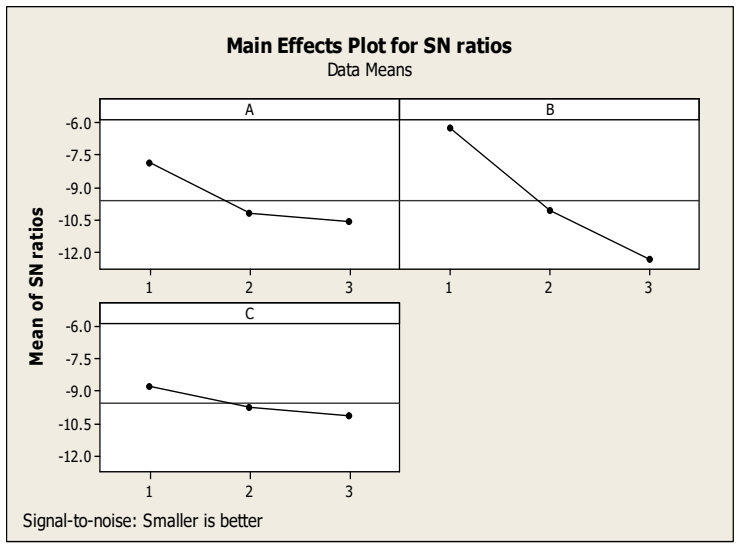

Fig 2: Main effect plot for $\mathrm{S} / \mathrm{N}$ ratios SR

Increasing the discharge current increases the MRR because greater spark discharge pressure causes melting, evaporation, and a significant impulse force in the 
sparking gap. Increased heat stress on the cathode and anode resulted in higher discharge current, leading the workpiece to expel more products [12].

During the machining process, it was found that the rise from 25 to 55 seconds in pulse on time, increases the MRR owing to a bigger discharge present, was passed for an extended period of time. In addition, it has been found that increasing from 55 to 80 seconds in the pulse on-time resulted in a decrease in the MRR. Which is due to the fact that increasing the breadth of the discharge volume decreases the amount of energy stored at the discharge point of the wok component [13, 15]. As a result, time pulses have an effect on this by increasing the melting and evaporation rates of gas bubbles and reducing the high-pressure strain on the work piece [1617]. A reduction in MRR has also been seen when reinforcement particles of $\mathrm{SiC}$ are entrapped in the spark gap, as shown by studies $[6,13,17]$.

Because melting and solid material are removed from the medium during this phase, and because the pulse off time has a very short impact on the discharge path, increasing the pulse off time results in a reduction in the mean residual resistance.

There is less content on the work with machined surface as a result of the short pulse off time period (i.e. $16 \mu$ s to $38 \mu \mathrm{s})$. Longer pulse lengths $(38 \mu \mathrm{s}$ to $56 \mu \mathrm{s})$ induce material to collect in the working channel, while shorter pulse durations (i.e. $16 \mu \mathrm{s}$ to $38 \mu \mathrm{s}$ ) cause material to accumulate in the working channel.

\subsection{Surface Roughness as a Function of Process Parameters}

Fig. 2 shows the main effect plot for the $\mathrm{S} / \mathrm{N}$ ratio SR with method parameters. As the rise in discharge current, there is an increase in the SR [6]. Which is resulted due to a sequence of subsequent spark discharges that caused in greater crater sizes and depths, leading in a high rate of material loss and a poor workpiece surface finish [12]. It has also been found that when the heart rate increases, so does the SR. High discharge energy (greater time consumed in machining zone) cause a channel of bigger plasma width and forces of impulse, which caused to melt more material and burn $\left(\mathrm{T}_{\text {on }} 80, \mathrm{~T}_{\text {off }} 56\right.$ micro-Sec $)$ and vaporises, resulting in huge shallow craters on the workpiece [13-14,18]. Additionally, as previously mentioned, increasing the trapping of $\mathrm{SiC}$ particles in the gap of the spark decreases the SR, which rises as the pulse off period is extended. It is because of the reduced discharge current during the pulse off time cycle, this results in reduced vaporisation over the work object's surface machined, resulting in a poorer surface polish. The MRR and SR are proportional to duration of the pulse, and low machining generated a high surface quality.

\section{Conclusions}

The EDM of SiC-strengthened Aluminum alloy 6061-T6 surface composites produced with Friction stir processing is effectively accomplished. The following are the conclusions obtained as a result of the tests. Increases in current enhance the surface composite's material removal rate, whereas reductions in MRR lengthen the pulse off time. MRR is increased with increasing the discharge current due to the greater discharge energy of spark. Greater heat loading on both the cathode and anode resulted in increased material ejection from the workpiece as a consequence of the increased discharge current. For better material removal rate, the parametric combination is 3-2-1. With increasing current and SR, Surface roughness values increase due to the greater spark discharge energy. 1-1-1 is a strong surface completed parametric mix.

\section{Acknowledgments}

The authors thank NIT Warangal, the DMRL Hyderabad, IICT Hyderabad, and DIAT Pune for their assistance.

\section{References}

1. S.Singh, Int $\mathrm{J}$ Adv Manuf Technol December 2012, Volume 63, Issue 9-12, pp 1191-1202

2. Bakes H, Benjamin D, Kirkpatrick C W. Metals Handbook. vol. 2. ASM. Metals Park: OH; 1979; 323.

3. Ravi, N., et al. "Microhardness and Microstructure Studies on Laser Surface Alloyed Aluminum Alloy with Ni-Cr.".

4. Ravi N, Sastikumar D, Subramanian N, Nath A K, Masilamani V., Materials and Manufacturing Processes15.3 (2000): 395-404.

5. M. Selvakumar, G.P. Rajamani, European journal of scientific research vol 91 issue 4,Dec,2012:580586.

6. M. Rozenek J. Kozak, L. DaÎbrowski, K. èubkowski, Journal of Materials Processing Technology 109 (2001) 367-370.

7. R. Karthikeyan , P.R. Lakshmi Narayanan, R.S. Naagarazan, Journal of Materials Processing Technology 87 (1999) 59-63.

8. Ross $\mathrm{P}$ J. Taguchi techniques for quality engineering. Mc Graw-Hill: New York; 1998: 2498.

9. Montgomery D C. Design and analysis of experiments. Wiley: New York; 1997: 395- 476.

10. Phadke Madhav S. Quality engineering using robust design prentice Hall. Englewood Cliffs: New Jersey; 1989: 41- 229.

11. A Devaraju, A Kumar, B.Kotiveerachari, Journal of Materials and Design 45 (2013) 576-585.

12. A Devaraju, A Kumar, B.Kotiveerachari, IJARM ISSN: 2231- 59501 (2011).

13. P. Narender Singh, K. Raghukandan. M. Rathinasabapathi, B.C. Pai, Journal of Materials Processing Technology 155-156 (2004) 1653-1657. 
14. B.Mohan, A.Rajadurai, K.G.Satyanarayana, Journal of Materials Processing Technology 155-156 (2002) 297-304.

15. Ko-Ta Chiang, Int J Adv Manuf Technol (2008) 37:523-533.

16. K. M. Patel, Pulak M. Pandey,P.V, Materials and Manufacturing Processes,23: 665-673, 2009.

17. K.M. Patel, Pulak M. Pandey,P.V Rao, Materials and Manufacturing Processes 23: 665-673, 2008.

18. B. H. Yan, C. C. Wang (2000) W. D. Liu and F. Y. Huang, Int J Adv Manuf Technol 2000.

19. C. Velmuruganl, R. Subramanian, S. Thirugnanam, B. Ananadavel, IJEST, Vol. 3, No. 8, 2011, pp. 87101. 